tumours are in some cases attended with a good deal of pain, felt in the course of the nerves and easily excited by pressure, a slight blow, or a quick movement. Excision is the only remedy, and it must in each case be uncertain how far it will be possible to effect that without injuring the structure of the nerve. Not long ago $I$ removed from within the sheath of the median nerve near the wrist, from a woman aged 48 , this spherical tumour; it is as large as an orange, presents a semi-opaque glistening appearance, not unlike brawn, with more opaque yellowish spots interspersed here and there. It resembled some of the varieties of encephaloid disease so closely that I should have been apprehensive as to the result had it not been gradually forming many years, during which time the woman enjoyed good health. It was attended with a good deal of pain and a shrivelled state of the fore and middle fingers. Some filaments of the nerve were removed with the tumour, nevertheless, the patient recovered completely, regaining the use of the hand; the fingers also were in course of time restored to their natural condition.

It has already been intimated that fibrous tumours occur in several other parts of the body besides the uterus, the periosteum, and the nerves. Here is one as large as a walnut and of spherical shape, growing from the inside of the dura mater, and causing an indentation in the surface of the brain. Sometimes they form in the substance of the testicle, the prostrate gland, the ovary, and even the walls of the alimentary canal. Very rarely are they to be met with in any other of the internal organs.

One point more requires to be specially mentioned in relation to these growths ; viz., their occasional liability to return after they have been to all appearance completely extirpated. Where this has taken place the tumour has, I believe, generally grown quickly in the first instance, has been composed of several detached portions, of which one or more may have been left behind in the first operation, or has consisted in a thickened morbid condition of the tissue in which the growths occurs, affecting a considerable area and probably not having such definite limits as these growths usually present. To the latter circumstance I have already directed your attention in speaking of fibrous tumours of the periosteum, and have said that the same feature is to be observed in some of the adipose tumours, thore particularly those under the skin. Whether these qualities are to be regarded as constituting an approximation to growths which we call malignant must remain a question till we are all able to define more clearly the real nature and characters of that class of diseases.

\section{CASES OF RHEUMATIC FEVER.}

\section{By SAMUEL S. DYER, Esa}

During the approaching winter, cases of rheumatic fever may afford to many of us abundant opportunities of testing the relative advantages of different modes of treatment.
In reporting the two following cases, it cannot be presumed that I am wishing to lay claim to anything like novelty of management, or originality of design, neither does the inducement to make them public proceed from any other cause than a desire to add testimony to the records in favour of treating acute rheumatism with large doses of Potassæ Nitras, by which I may call additional attention to the benefits resulting from its administration, and thereby induce others to test its remedial powers in treating similar cases. I waited some time before reporting the result of my own trial of it, thinking another case or two might give me an opportunity of adding weighty and indisputable facts in proof of its great utility; but not having since had the chance of giving it, I will no longer delay publishing the short notes $I$ took at the time of attending the patients, trusting these may be taken as an example of what would most probably occur in any greater number.

I was led to use it in the first instance from having read some reports of a case treated in this way in King's College Hospital, by Dr. Budd. Presuming that rheumatic fever is one of a large class of diseases, dependent upon the circulation of a poison in the blood, from the non-elimination of this deleterious agent, we shall not be far wrong if we make a guess that this materies morbi is in some way decomposed by the medicine, or that the usual excreting organs of such a poison are stimulated to increased action by the means we use, that the cause is thus removed, and the disease (the effect) ceases. And here I acknowledge my supposition must end, as I can advance no tabular formula of the elective affinity exerted between the com ponent elements of nitrate of potash and lithic acid; such, if any such there be, I leave to be determined by wiser heads.

\section{Case I.}

Selina Mintey, aged 27, married, mother of three children, youngest nine weeks old.

April 28th, 1850.-After walking to church, a distauce of a mile, on a cold windy day, was taken with shivering, fever, pain in the back and shoulders.

May 1st.-Found her suffering from a severe attack of rheumatic fever, much pain in wrists, elbows, and knees, which joints were swollen, red, and tender; quick pulse; sour-smelling perspiration; bowels confined; urine scanty, loaded with lithates; heart sounds natural.

She had rheumatic fever seven years ago, when she was confined to the bed six weeks, to the house thirteen, and was attended on that occasion by my father and myself. She is now anticipating such another illness, and is very desponding. R. Pulv. Catharticus, scr. j., statim; R. Pot. Nitratis, scr. j. ; Mist. Camph., oz. iss., quartis horis posteâ. Wrap the affected joints in new flannel, and live upon milk, gruel, mutton broth, \&c.

May 3rd.-Wrists less painful; ankles now inflamed and swollen. Continue the draughts.

5th.-A little better, is in less pain, and can bear being moved in the bed; urine more abundant and clear; pulse 100; no cardiac complication; bowels 
open; free diaphoresis, with less of that characteristic odour.

8th.-Has continued quite free from pain ever since the last visit, moves about the bed with ease and comfort, and considers the weakness to be her only ailment. Pulse 80 ; heart sounds natural. Substitute for the Potassæ Nitras (which she has taken to the present time) carbonate of ammonia, in infusion of quassia, three times a day.

\section{Case II.}

Thomas Barton, aged 32 years, a gatekeeper on the South Western Railway, sent for me, September 16th, 1850 , and states that he has been ill three days. Was first taken with rigors, pain in the limbs, and symptoms of general cold. He now complains of pain in the left knee and right ankle, which has been very acute the last two days. These joints are swollen, red, hot, and tender, and not benefitted by repeated infrictions of "Dredge's Heal-all." Much thirst and heat of skin; no difficulty of breathing; pulse 100 ; tongue furred; bowels constipated; urine depositing lithates. $R$. Pulv. Cath., scr. j., statim.-R. Pulv. Pot. Nit., scr.j., quartis horis ex oz. iss. Mist. Camph. Wrap the joints in flannel and take slops.

17th.-Much the same; urine scanty and high coloured; sediment abundant; bowels freely open. Diaphoresis.

19th.-Is in less pain in the knee and ankle; feels a stiffness of the shoulders; has perspired profusely; urine more abundant and clear.

21st.-Much better. Continue medicine.

23rd.-Walked out. Omit the Nit. Pot. and take a tonic for a few days.

28th.-Walked to and from the surgery, a distance of two miles, and resumed his duties.

Ringwood, October 21, 1850.

observations ON

HYDATID DISEASE OF THE ITVER.

By P. M. DUNCAN, M.B.,

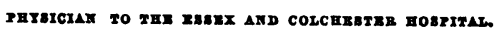

I. Illustrative Cases.-II. Descriptive and Minute Anatomy of Acephalocyst Hydatids; Theory of their Entrance into the System; Remarks upon their Generation, Development, Distribution, Progress, and Decadence.-III. The Symptoms, Diagnosis, Prognosis, and Treatment of the Disease.

\section{PART I.}

Tre interesting paper, embodying observations and inquiries concerning hydatids of the liver, by $\mathrm{Dr}$. E. Lyon, and which lately appeared in this journal, has tempted me to put in form some notes on the same subject, which I hope will draw further remarks from those who have had extensive opportunities of studying this important subject.

Case 1.-About four years ago I opened, in company with Messrs. Hunter and Thornton, of Margate, the body of a man accidentally killed. Besides the fractured skull, which caused his death, we found four large and superficial hydatid tumpurs of the liver. The remaining organs were healthy. These tumours were in the right lobe, were close together, and nearly equal in size. One of them was carefully examined. It was perfectly globular in shape, and nearly two inches in diameter; was partly received into a cup-shaped depression in the substance of the liver, and the rest had pushed up, and was covered by the capsule of the organ; of a glistening white colour; it gave an odd sort of thrill to the finger when percussed; and was evidently filled tensely with a colourless limped fluid. The substance of the liver in immediate contact with the fibrous outside of the tumour was apparently healthy ; the fibrous membrane, however, could not be readily separated from it, as there was evidently a vascular connexion.

On opening the tumour, a jet of colourless fluid occurred, and an albuminous and tolerably firm tissue was seen to line internally the whole of the fibrous membrane which formed the external wall of the tumour. The fluid which remained after the puncture was colourless, limped, contained no albumen, and was slightly saline. At the bottom of this great cyst, and floating in the fluid, were hundreds of small bodies about the size of the smallest pin's head; under a moderate magnifying power they turned out to be echinococci,-oval, transparent, colourless, entozoa. The surface of these creatures was destitute of any hair, spine, or sucking apparatus; but a canal passed from the anterior part inwards to a circlet of hooks, which, when decomposition occurred, was pushed up through the canal, and became external, forming a sort of headpiece to the creature.

Many of these echinococci were found adherent to the albuminous tissue in immediate contact with the fluid. These hydatid tumours then consisted of an external dense membrane, an internal albuminous tissue, and a fluid in which echinococci abounded.

The external membrane had no connexion, except that of simple contact with the internal, and was evidently laminated, and consisted of concentric layers; the remains of bloodvessels could be traced in it, and in more than one spot on its internal surface; and of course in contact with the albuminoid membrane were hard patches, of a light yellow colour, which looked like the deposit occasionally seen in the arteries, and which consisted of a mass of crystals and oil. No structure could be made out in the internal membrane, which appeared to be easily torn. Echinococci were seen in contact with it.

There could be no doubt that these tumours were hydatids-acephalocysts-which were simple, not compound, as were those in the following case :-

Case 2.-The subject of mitral disease of the heart, he died dropsical, and suffered a little before death from congestion of the liver. In the midst of the right lobe of the liver two large hydatid tumours were discovered; in each the external fibrous membrane was dense, and sepa- 